\title{
PERANCANGAN MEJA PUTAR ROLL WELDING SEBAGAI ALAT BANTU PENGELASAN (STUDI KASUS : ART WELDING PT MECO INOXPRIMA)
}

\author{
Imam Kholiq ${ }^{1}$, Alven Safik Ritonga ${ }^{2}$ \\ ${ }^{1}$ Universitas Wijaya Putra,Fakultas Teknik ,Program Studi Teknik Mesin \\ ${ }^{2}$ Universitas Wijaya Putra,Fakultas Teknik ,Program Studi Teknik Komputer \\ e-mail 1: imamkholik@uwp.ac.id , e-mail 2: alvensafikritonga@uwp.ac.id
}

\begin{abstract}
ABSTRAK
engelasan yang menghasilkan sambungan yang berkualitas dan sangat

$\mathrm{P}$ memungkinkan untuk menyambung logam dengan pengelasan pada berbagai bentuk dan posisi. Oleh karena itu proses pengelasan harus memerlukan alat bantu penyangga material yang praktis dan sesuai dengan kebutuhan segala posisi pengelasan yang akan memudahkan dan memberikan kenyamanan welder dalam mengelas. Sehingga menghasilkan hasil las yang maksimal dan berkualitas (hasis las yang bagus secara visual) pada penelitian ini jenis sambungan yang digunakan yaitu sambungan sudut dengan tujuan merancang dan membuat alat bantu untuk mendapatkan hasil pengelasan sambungan dan membandingkan distorsi yang terjadi antara menggunakan alat bantu meja putar dan tanpa menggunakan alat bantu. Pada penelitian ini digunakan jenis pengelasan Gtaw dengan merek D.C ARC WELDER bertipe Bz-300F-3 dan RD-260 AWS A5.22:2012 ER2209 berdiameter 2,4mm sebagai Fillernya. Kajian dibatasi pada perancangan dam pembuatan alat serta pengukuran distorsi yang dilakukan sebanyak 20 kali. Pengukuran distorsi menggunakan alat dial indikator dengan titik awal/titik nol pada ujung benda uji dan titik akhir pada daerah sambungan las.Hasil menunjukkan bahwa penggunaan alat bantu meja putar roll welding dapat mengurangi terjadinya distorsi. Didapat nilai terkecil distorsi menggunakan alat bantu meja putar roll welding yaitu sebesar 0,22 derajat, sedangkan nilai terkecil distorsi tanpa penggunann roll welding yairu sebesar 1,44 derajat. Serta penggunaan alat bantu meja putar roll welding dapat mengurangi cacat pengelasan mereduksi waktu setup dan dapat meningkatkan volume produksi, menghilang kan cacat las yang berakibat pada penurunan biaya produksi, sehingga cukup layak dan efisien dari segi ekonomi.
\end{abstract}

Kata Kunci: Alat bantu, Roll Welding, Distorsi berkurang, Produksi meningka 


\section{PENDAHULUAN}

\subsection{Latar Belakang Masalah}

Apabila secara spesifik membahas sebuah infrasruktur degan bahan dasar logam maka pengelasan adalah metode penyambungan yang paling banyak dipakai. Pengelasan yang menghasilkan sambungan yang berkualitas dan sangat memungkinkan untuk menyambung logam dengan pengelasan pada berbagai bentuk dan posisi. Oleh karena itu proses pengelasan harus memerlukan alat bantu penyangga material yang praktis dan sesuai dengan kebutuhan segala posisi pengelasan yang akan memudahkan dan memberikan kenyamanan welder dalam mengelas. Sehinga mengahasilkan hasil las yang maksimal dan berkualitas (hasil las yang bagus secara visual:

-Tinggi tidak lebih dari 3mm.

-Rigi-rigi rata.

-Tidak terjadi distosi (perubahan bentuk)/

-Tidak terdapat cacat las pada permukaan

seperti : undercut, porosity, crack, underfill, spatter.

\subsection{Rumusan Masalah}

Berdasarkan latar belakang diatas maka dapat dirumuskan permasalahan dalam penelitian ini yaitu bagaimana mencari solisi : mengurangi distorsi, menekan biaya (biaya mahal (over head), pekerjaan manufaktur diluar jadwal (tidak on time schedule) hasil pekerjaan tidak memuaskan pelangan (banyak klaim), hasil pekrjaan manufakture tidak berkualitas, hasil las-lasan jelek ( banyak cacat lasan-lasan) welder sulit mencari posisi pengelasan. Merancang, membuat alat bantu meja putar Roll welding sebagai alat Bantu Pengelasan. Untuk itu banyak perusahaan dibidang industri manufaktur mencoba mencari cara untuk menekan biaya produksi dan mempercepat proses produksi tanpa mengurangi kualitas produk yang dihasilkan. Sehinga banyaknya bermunculan alat-alat bantu yang dapat membantu dan bahkan menggantikan pekerjaan manusia tersebut. Namun tidak semua pekerjaan yang ada sekarang sudah memiliki alat bantu yang dapat memudahkan pekerjaan tersebut. Bahkan dalam beberapa kegiatan produksi manufaktur terdapat beberapa pekerjaan yang menuntut adanya penggunaan alat bantu, salah satunya adalah alat bantu pengelasan. Dengan memperhatikan kenyataan diatas maka perlu dilakukan perancangan dan pembuatan alat bantu roll welding dalam proses pengelasan yang mampu menjamin hasil pengelasan yang benar,dengan proses yang cepat dan mudah. Dengan kata lain pengerjaan proses pengelasan akan lebih mudah untuk mendapatkan kualitas produk yang lebih tinggi dengan tidak adanya cacat pada bagian pengelasan benda.kerja, ataupun laju produksi yang lebih tinggi. Dengan demikian, efisiensi proses pengelasan suatu produk dapat ditingkatkan (mereduksi waktu setup) melalui perancangan alat bantu roll weding pada proses pengelasan.

\subsection{Target Penelitian}

Rancangan alat bantu pengelasan meja putar Roll Welding yang dapat memberikan kenyamanan posisi welder dalam praktek pengelasan di berbagai macam posisi, ditentukan konsep alat bantu yang dirancang harus memenuhi hal-hal sebagai berikut:

a. Sederhana, mudah dioperasikan.

b. Menurunkan biaya fabrikasi manufaktur.

c. Menghasilkan part komponen berkualitas tinggi ( tidak ada cacat las pada proses

d. pengelasan ) secara konsisten.

e. Menaikkan laju produksi. (jadwal produksi tepat waktu (on time Schedul).

f. Mencegah penggunaan/pemasangan yang salah.

g. Mempermudah pengelasan (posisi pengelasn yang paling mudah ).

h. Mennaikan effisiensi (hasil las bekualitas,tidak ada klaim)

i. Pelanggan puas.

j. Mengurangi distorsi/

\subsection{Luaran dan Kontribusi Penelitian}

1. Menghasilkan sebuah laporan Akhir 
2. Menghasilkan HKI (minimal Hak Cipta )

3. Memudahkan posisi pengelasan Welder sesuai dengan posisi yang diinginkan berdasarkan kenyamanan.

4. Memudahkan dalam peletakan material terhadap posisi pengelasan.

5. Mengetahui cara membuat Alat bantu ( Roll welding ).

\subsubsection{Alat bantu meja putar (Roll welding)}

Perancangan didasarkan dengan gagasan atau ide ingin memberikan kontribusi terhadap riset unggulan internal Universitas Wijaya Putra, yaitu menciptakan alat bantu pengelasan. Rancangan sementara seperti pada Gambar 1. Secara umum dalam perencanaan ini benda yang akan dilas dijepit, diputar menggunakan system transmisi kemudian pemegang kawat las (gun) diarahkan pada part ( komponen ) yang akan dilas atau disambung.

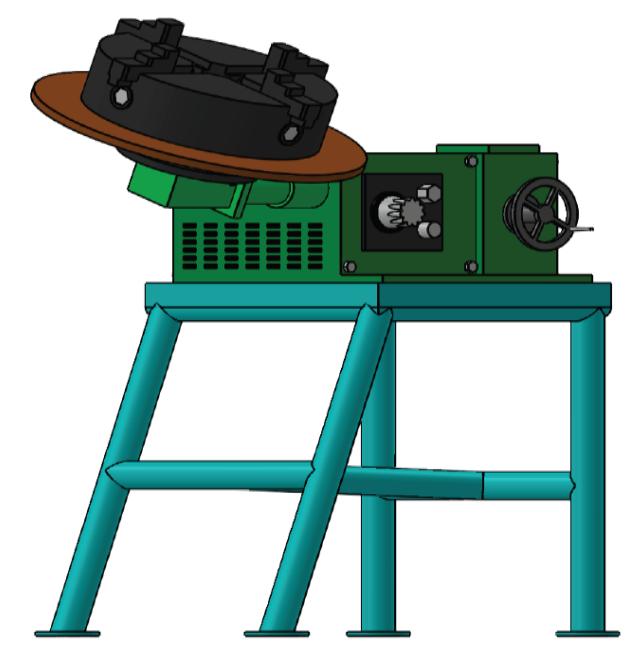

Gambar 1. Alat bantu meja putar ( Roll welding )

\section{TINJAUAN PUSTAKA}

Saat ini perkembangan ilmu pengetahuan dan teknologi berdampak pada kemajuan industri manufaktur yang diharuskan untuk dapat menghasilkan produk dengan cara yang lebih mudah, cepat, dan murah. Untuk itu banyak perusahaan dibidang industri manufaktur mencoba mencari cara untuk menekan biaya produksi dan mempercepat proses produksi tanpa mengurangi kualitas produk yang dihasilkan.

Contoh nyata yang paling mudah untuk dilihat di antaranya adalah banyaknya bermunculan alat-alat bantu yang dapat membantu dan bahkan menggantikan pekerjaan manusia tersebut. Namun tidak semua pekerjaan yang ada sekarang sudah memiliki alat bantu yang dapat memudahkan pekerjaan tersebut. Bahkan dalam beberapa kegiatan produksi manufaktur terdapat beberapa pekerjaan yang menuntut adanya penggunaan alat bantu, salah satunya adalah pengelasan (Arifin dkk, 2014). Dengan memperhatikan kenyataan diatas maka perlu dilakukan perancangan dan pembuatan alat bantu roll welding dalam proses pengelasan yang mampu menjamin hasil pengelasan yang benar, dengan proses yang cepat dan mudah. Dengan kata lain pengerjaan proses pengelasan akan lebih mudah untuk mendapatkan kualitas produk dengan yang lebih tinggi tidak adanya cacat pada bagian benda kerja, ataupun laju produksi yang lebih tinggi. Dengan demikian, efisiensi proses pengelasan suatu produk dapat ditingkatkan mereduksi waktu setup) melalui perancangan alat bantu roll welding pada proses pengelasan.

\section{1 Tinjauan Pustaka}

Meja putar las Roll welding adalah peralatan produksi yang menempatkan, memegang dan menyangga benda kerja secara kuat sehingga pekerjaan yang diperlukan bisa dilakukan (Arifin, 2008). Fungsi utama dari meja putar roll welding adalah memegang benda yang akan dilas pada saatnya ataupun sebelumnya.

Distorsi adalah terjadinya perubahan bentuk atau penyimpangan bentuk oleh panas,termasuk akibat pengelasan. Terjadinya pemuaian benda kerja mengakibatkan melengkung atau tertarik bagian-bagian sekitar benda kerja las. Hal ini karena semua logam akan mengalami pendiginan. Sehingga seorang operator atau pekerja las harus 
mememiliki kemampuan untuk mengendalikan pemuaian dan penyusutn agar tidak berlebihan pada benda kerja.

\section{Cara mencegah Distorsi Las}

1. Koefisien Muai Panjang

Adalah jumlah pertambahan panjang dari suatu logam karena mengalami perubahsan suhu setiap 1 derajat celcesius. Hal-hal yang mempengaruhi perubahan panjang logam adalah :

- Jenis logam

- Perubahan temperatur

- Perubahan panjang yang kesegala arah

2. Pemanasan dan pendiginan

- Pemanasan dan pendiginan benda bebas

- Pemanasan dan pendiginan benda tertahan

- Faktor penyebab distorsi las

1. Tegangan sisa.

2. Pengelasan atau pemotongan dengan panas.

3. Jenis - jenis Distorsi.

A. Distorsi arah melintang.

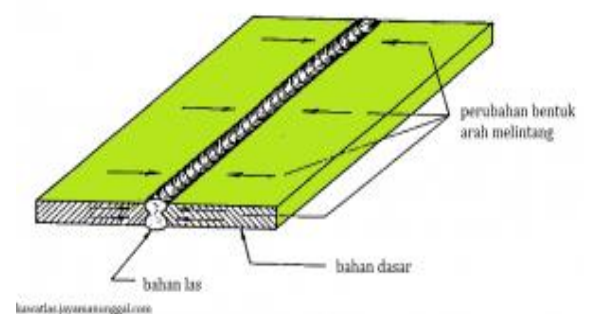

B. Distorsi arah memanjang.

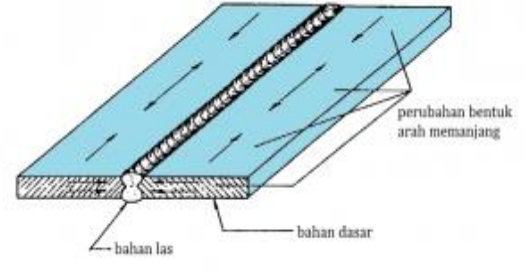

C. Distorsi arah menyudut.

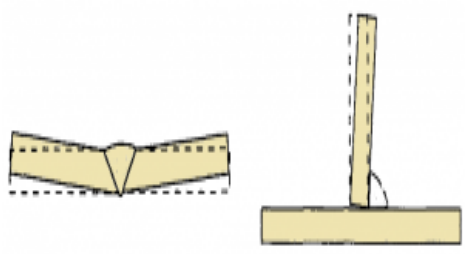

\section{METODE PENELITIAN}

Uraikan secara rinci metode yang akan digunakan meliputi tahapan-tahapan penelitian, lokasi penelitian, peubah yang diamati/diukur, model yang digunakan, rancangan penelitian, serta teknik pengumpulan dan analisis data. Penelitian ini dilaksanakan pada bulan Mei 2019 sampai dengan bulan Desember 2019. Lokasi penelitian ini dilaksanakan di PT MECO INOXPRIMA Berigin Bendo Trosobo Sidoarjo Jawa Timur.

\subsection{Metode Penelitian dan Eksperimen}

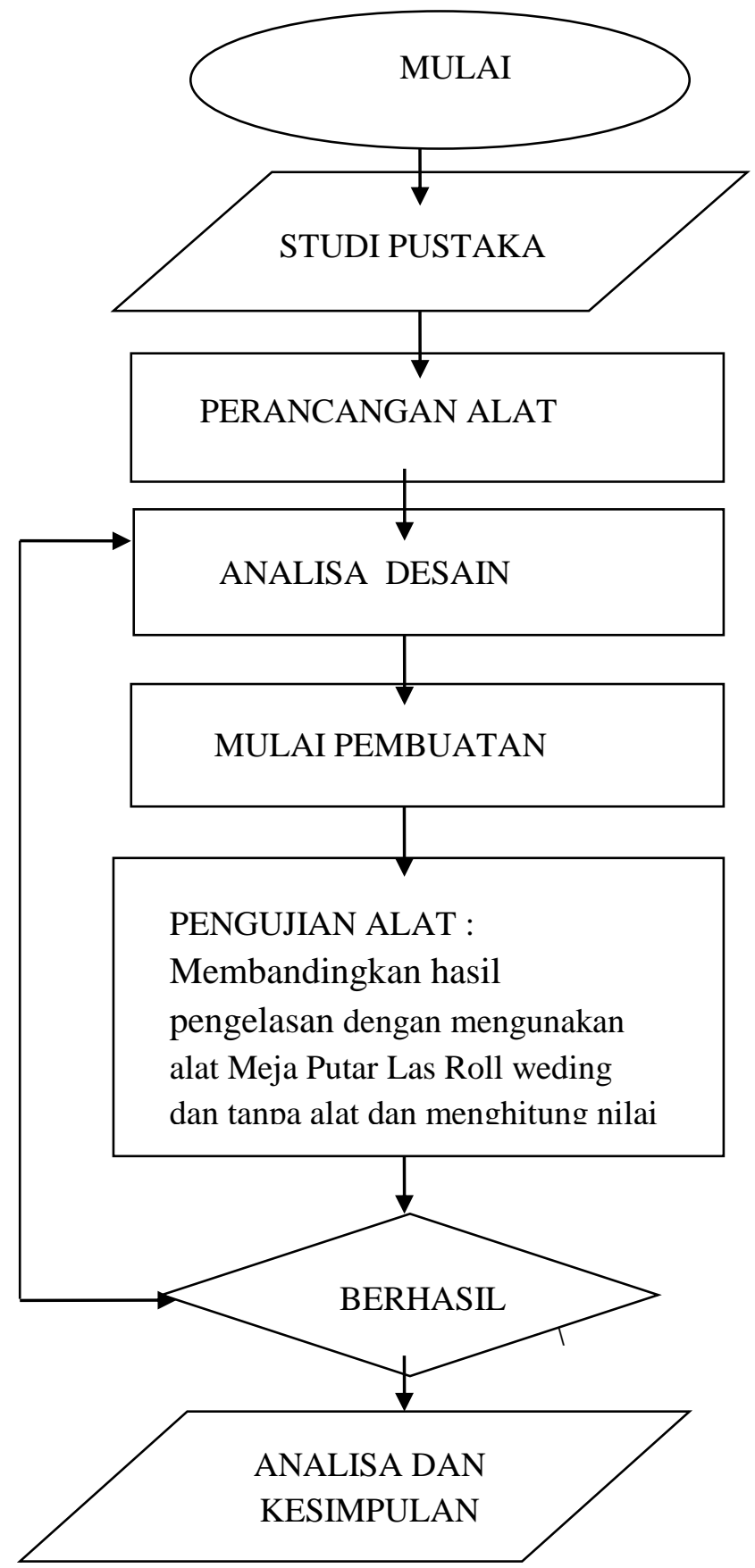




\subsubsection{Desain Alat Bantu Lama}

Berikut beberapa gambar alat bantu pengelasan yang lama:

a. Pada gambar dibawah ini menunjukkan bahwa posisi welder dalam mengelas terlihat tidak nyaman karena alat bantu yang lama hanya berbentuk seperti meja dan tidak bisa di adjust.

b. Pada gambar dibawah ini menunjukkan bahwa peletakan material tidak praktis karena menggunakan tig weld
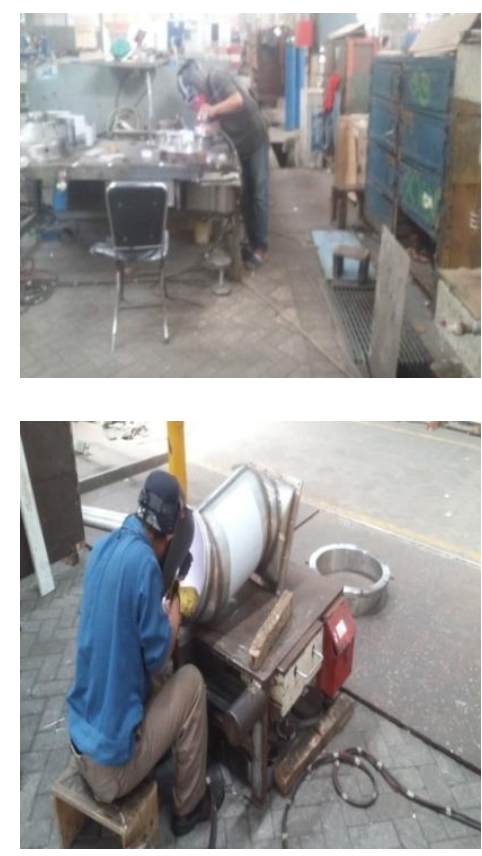

Gambar 2. Tanpa Alat bantu

\subsubsection{Desain Alat Bantu Meja Putar Roll Welding}

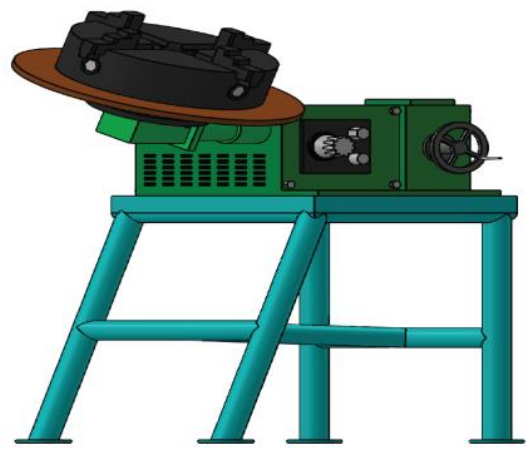

Gambar 3. Alat bantu Meja putar ( Roll welding)
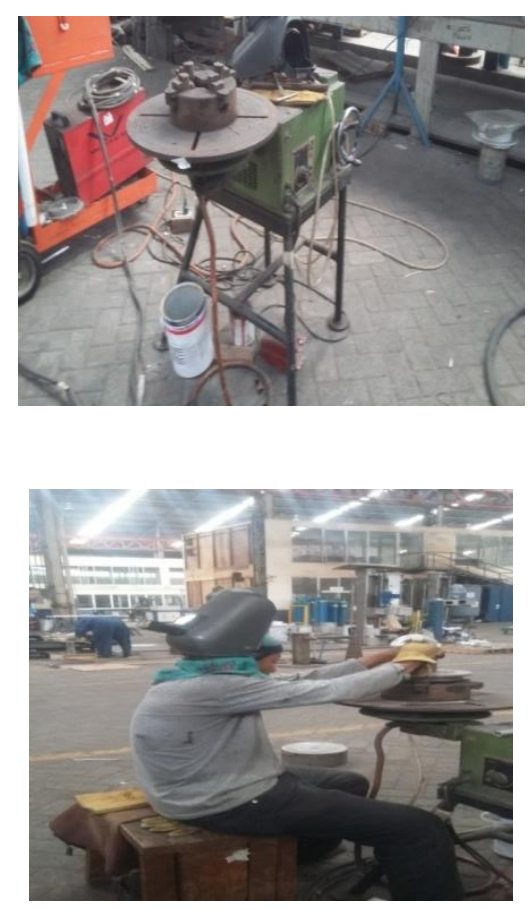

Gambar 4. Alat bantu Meja putar ( Roll welding ) digunakan

\subsection{Eksperimen}

Desain alat bantu selalu berkembang karena tidak ada satu alat yang mampu memenuhi seluruh proses manufaktur. Dari sini ditentukan konsep alat bantu yang dirancang harus memenuhi hal-hal sebagai berikut:

a. Sederhana, mudah dioperasikan.

b. Menurunkan biaya manufaktur. (lebih efisien)

c. Menghasilkan part berkualitas tinggi secara konsisten.

d. Menaikkan laju produksi.

e. Foolproof, mencegah penggunaan /pemasangan yang salah.

f. Mengurangi distorsi, cacat las

\section{Hasil dan Analisa}

\subsection{Analisa Pada Clamp}

Posisi pencekam selalu bersentuhan dengan benda kerja pada posisi yang rigid.

Untuk menghindari defleksi benda kerja harus ditahan menggunakan alat bantu. 


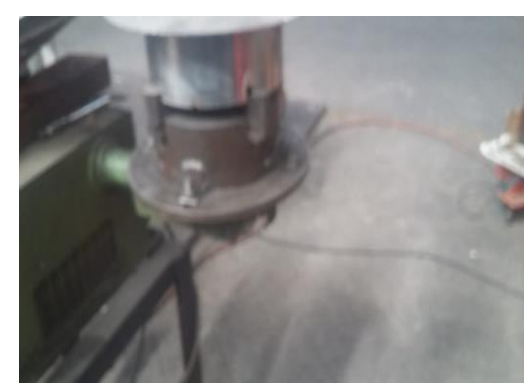

Gambar 5. Daerah clamp yang bersentuhan dengan benda kerja.

Material : Baja karbon rendah :

Panjang komponen $\quad: 143,23 \mathrm{~mm}$

Lebar komponen $\quad: 50 \mathrm{~mm}$

Tegangan pada clamp jadi $F=1817415,86 \mathrm{~N}$

$$
\begin{aligned}
A & =7161.5 \mathrm{~mm}^{2} \\
\sigma & =\frac{F}{A}
\end{aligned}
$$

Maka, $F=1817415,86 \mathrm{~N}$

$A=7161.5 \mathrm{~mm}^{2}$

$$
\begin{aligned}
& \sigma=\frac{1817415,86 \mathrm{~N}}{7161,5 \mathrm{~mm}^{2}} \\
& \sigma=253,77 \mathrm{~N} / \mathrm{mm}^{2}
\end{aligned}
$$

\subsection{Analisa pada set-block}

Sebagai alat yang memposisikan benda kerja pada Alat bantu meja putar las agar benda kerja menjadi rigid atau kaku. daerah set-block yang bersentuhan dengan benda kerja.

Material : Baja karbon rendah :

Panjang komponen $: 100 \mathrm{~mm}$ Lebar komponen $\quad: 60 \mathrm{~m}$ Tegangan pada clamp jadi $F=1817415,86 \mathrm{~N}$ $A=6000 \mathrm{~mm}^{2}$

$$
\begin{aligned}
& \sigma=\frac{F}{A} \\
& \sigma=\frac{1817415,86 \mathrm{~N}}{6000 \mathrm{~mm}^{2}} \\
& \sigma=302,9 \mathrm{~N} / \mathrm{mm}^{2}
\end{aligned}
$$

\subsection{Analisa Pada Roller Penggerak}

Roller penggerak digunakan untuk menggerakkan clamp, batang ini memiliki ulir sehingga dapat mendorong dan menarik clamp.

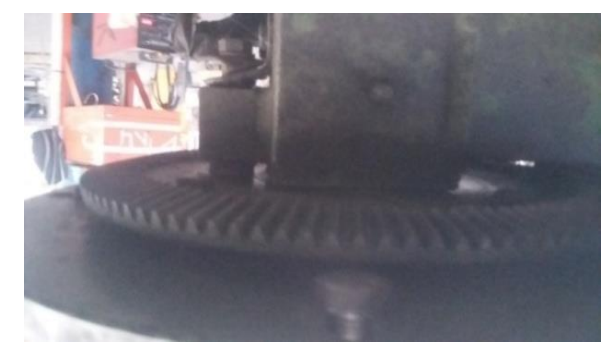

Gambar 6. Roller penggerak.

Material : Baja karbon rendah

Massa

: $20,164 \mathrm{Kg}$

Diameter komponen : $20 \mathrm{~mm}$

Tegangan pada clamp

Maka,

$$
\begin{aligned}
& \sigma=\frac{F}{A}=\frac{4 F}{\pi \cdot d^{2}} \\
& \sigma \quad=\frac{7269663,44 N}{1256^{2}} \\
& \sigma \quad=5787,94 \mathrm{~N} / \mathrm{mm} 2
\end{aligned}
$$

4.4. Analisa Toleransi Pada UlirUntuk ulir luar daerah toleransinya adalah e, $\mathrm{g}$ dan $\mathrm{h}$.

Sedangkan untuk ulir dalam daerah toleransinya adalah $\mathrm{G}$ dan $\mathrm{H}$.

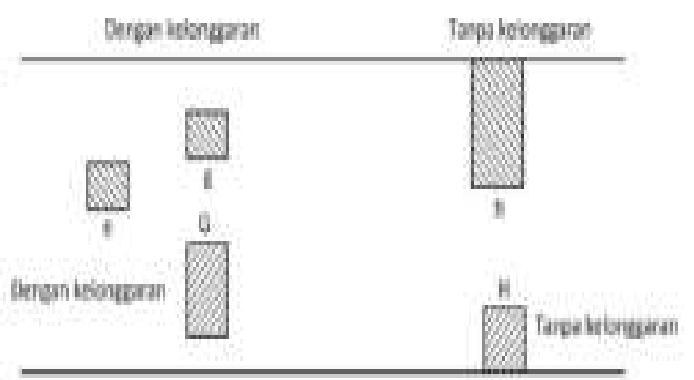

Gambar 7. Posisi daerah toleransi ulir luar dan ulir dalam.

Ulir yang digunakan dalam penelitian ini yaitu berjenis M20 dengan spesifikasi sebagai berikut:

Tabel 1. Spesifikasi Ulir M 20

\begin{tabular}{|c|c|c|c|c|c|}
\hline $\begin{array}{c}\text { Diamet } \\
\text { er } \\
\text { Nomin } \\
\text { al d=D }\end{array}$ & $\begin{array}{c}\text { Gan } \\
\text { g }\end{array}$ & $\begin{array}{c}\text { Diamet } \\
\text { er } \\
\text { Tengah }\end{array}$ & $\begin{array}{c}\text { Ulir } \\
\text { luar } \\
\text { Diamet } \\
\text { er } \\
\text { Terkeci } \\
1(\text { di) }\end{array}$ & $\begin{array}{c}\text { Ulir } \\
\text { dalam } \\
\text { Diamet } \\
\text { er } \\
\text { Terkeci } \\
1\end{array}$ & $\begin{array}{c}\text { Ulir } \\
\text { dalam } \\
\text { Diamet } \\
\text { er } \\
\text { Mata } \\
\text { Bor }\end{array}$ \\
\hline M20 & 2.5 & 18,37 & 16,93 & 17,29 & 17,5 \\
\hline
\end{tabular}


Maka, Toleransi yang terjadi pada ulir batang penggerak yaitu sebesar $174 \mu \mathrm{m}$ untuk ulir luar dan $229 \mu \mathrm{m}$ untuk ulir dalam.

Bagian-bagian yang telah dirancang dan dibuat akan digabungkan dengan komponen komponen utama lainnya. Berikut ini merupakan alat bantu Alat bantu Meja Putar las Roll WELDING yang telah selesai dibuat dan di rangkai.

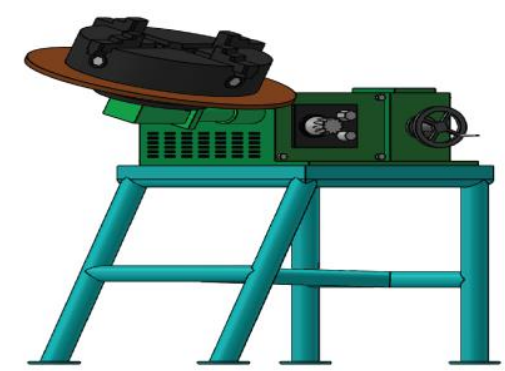

Gambar 8. Alat bantu Meja putar ( Roll welding )

\subsection{Pengujian Alat}

Adapun pengujian pada alat ini adalah untuk mengetahui apakah elemen-elemen yang ada pada alat bantu Alat bantu meja putar las Roll WELDING proses pengelasan sambungan $\mathrm{T}$ dapat bekerja dengan baik, dengan membandingkan hasil pengelasan yang pendinginannya menggunakan Alat bantu meja putar las Roll WELDING dan tanpa Alat bantu meja putar las Roll WELDING. Adapun proses-proses pengujian alat meliputi : persiapan mesin dan alat, persiapan benda uji, analisa, kesimpulan dan selesai.

\subsubsection{Persiapan Benda Uji}

Benda kerja yang digunakan dalam penelitian ini, yaitu nozzle yang berukuran diameter 150 $\mathrm{mm}$ dengan ukuran panjang $200 \mathrm{~mm}$.

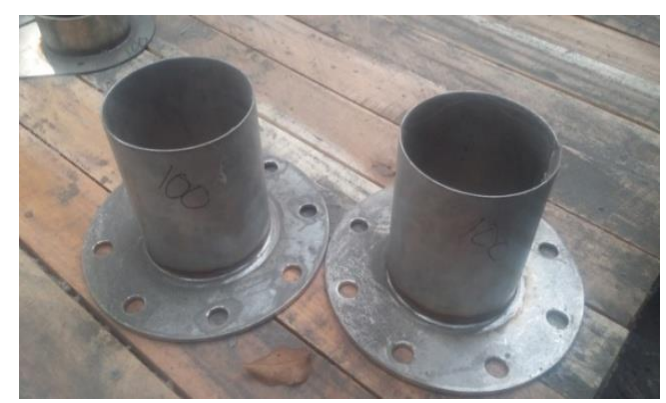

Gambar 9. Nozzle

\subsubsection{Persiapan Alat}

Adapun alat-alat yang digunakan guna menunjang penelitian adalah sebagai berikut:

a. Mesin Las Jenis mesin las yang digunakan pada pengujian alat bantu pegang ini adalah Pengelasan GTAW (gas Tungsten Arc Welding) atau biasa disebut las Argon.

b. Dial Indikator Dial indikator adalah alat ukur yang dipergunakan untuk memeriksa penyimpangan yang sangat kecil dari bidang datar, bidang silinder atau permukaan bulat dan kesejajaran.

\subsection{1 Pelaksanaan Pengujian}

Tahapan Pengujian :

1. Tahap awal pengujian yaitu menyiapkan alat-alat yang akan digunakan selama proses pengujian.

2. Benda uji yang digunakan dipotong panjangnya menjadi $200 \mathrm{~mm}$, sedangkan tebal benda uji yaitu $3 \mathrm{~mm}$.

3. Pada pengujian pengelasan menggunakan Alat bantu las Roll WELDING, benda uji ditempatkan pada 2 buah sisi sehingga benda uji tersebut memiliki sudut 900, lalu keratkan benda uji dengan memutar batang penggerak agar clamp dapat menahan benda uji.

4. Pada pengujian pengelasan tanpa menggunakan Alat bantu las Roll WELDING, 2 buah benda uji diletakkan diatas permukaan datar, gunakan mistar siku untuk mendapatkan sudut 900. Benda uji siap dilakukan proses pengelasan.

5. Setelah benda uji siap, proses pengelasan dapat dilakukan dengan menggunakan elektroda berjenis E6013, Voltase 20-30V, travel speed $60 \mathrm{~mm} / \mathrm{min}$ serta variasi Arus (A) yaitu $100 \mathrm{~A}, 125 \mathrm{~A}$ dan $150 \mathrm{~A}$.

6. Menjalankan proses pengelasan sesuai dengan parameter dan variasi yang telah ditentukan.

7. Ketika menjalankan proses, hitung perbandingan waktu setup dan waktu proses pengelasan.

8. Mengukur distorsi dari setiap benda uji dengan menggunakan dial indikator.

Pengukuran distorsi dapat dilakukan sebagai berikut: 
a. Benda uji yang telah dilas diletakkan diatas meja datar.

b. Agar benda kerja tidak bergerak, maka dicekam.

c. Benda uji diukur dengan dial indikator pada ujung benda uji yang mana menjadi titik 0 (nol) atau titik awal pengukuran.

d. Dial indikator mengukur daerah las dari benda uji yang merupakan titik akhir pengukuran.

e. Didapatkan selisih ukuran yang merupakan nilai dari distorsi.

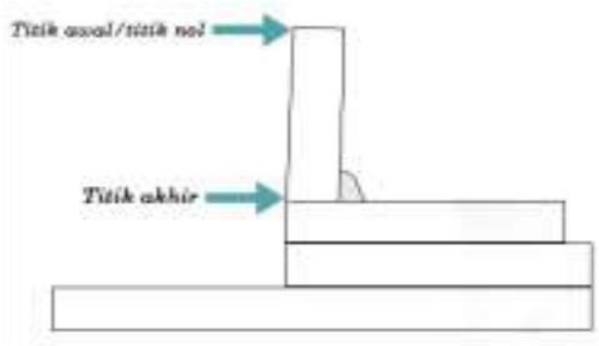

Gambar 10. Pengukuran distorsi

9. Mengolah data hasil pengelasan dan hasil pengukuran yang diperoleh secara statistik.

10. Memasukkan nilai tersebut kedalam tabel dan kemudian dibuat grafik masingmasing variasi terhadap nilai distorsi. Menganalisa hasil penelitian untuk mendapatkan kesimpulan dari setiap variasi parameter tersebut dan menentukan apakah Alat bantu las Roll WELDING yang dibuat berhasil menahan laju distorsi pada benda uji.

\subsubsection{Hasil Pengujian Alat}

Waktu

Pada pengujian ini didapat waktu setup । waktu proses pengelasan, dimana $h_{i}$ (detik) pengujian memperlihatkan perbandingan waktu yang terjadi antara menggunakan Alat bantu las Roll WELDING dan tanpa menggunakan Alat bantu las Roll WELDING. Kemudian setelah membandingkan waktu dengan menggunakan dan tanpa menggunakan Alat bantu las Roll WELDING. dilakukan analisa kelayakan ekonomis yang gunanya agar mengetahui apakah Alat bantu las Roll WELDING atau Alat bantu las Roll WELDING yang dibuat layak untuk digunakan secara ekonomi.

\subsubsection{Analisis Perbandingan Waktu}

Setelah melakukan proses perhitungan waktu setup tanpa menggunakan Alat bantu meja putar ROLL WELDING dan waktu setup dengan menggunakan Alat bantu pada saat pengujian alat, maka dapat diketahui perbandingan waktu setup yang terjadi. Selain itu, terdapat juga waktu proses pengelasan yang dilakukan dengan perbandingan proses pengelasan tanpa menggunakan Alat bantu meja putar Roll Welding dan proses pengelasan menggunakan alat bantu meja putar Roll Welding. Perbandingan waktu setup dan waktu proses dapat dilihat pada tabel berikut.

Tabel 2. Perbandingan waktu setup dan waktu proses

\begin{tabular}{|l|c|c|}
\hline $\begin{array}{l}\text { Menggunakan Alat } \\
\text { bantu Las Meja putar } \\
\text { Roll Welding }\end{array}$ & \multicolumn{2}{|c|}{$\begin{array}{l}\text { Tanpa Menggunakan } \\
\text { Alat bantu Las }\end{array}$} \\
\hline $\begin{array}{l}\text { Spesimen I III } \\
\text { II IV }\end{array}$ & \multicolumn{2}{|c|}{ V } \\
\hline $\begin{array}{l}\text { Waktu Setup } \\
\text { (detik) }\end{array}$ & 26,112 & 43,088 \\
\hline $\begin{array}{l}\text { Waktu Proses } \\
\text { (detik) }\end{array}$ & 25,804 & 20,581 \\
\hline Total (detik) & 51,916 & 63,669 \\
\hline
\end{tabular}

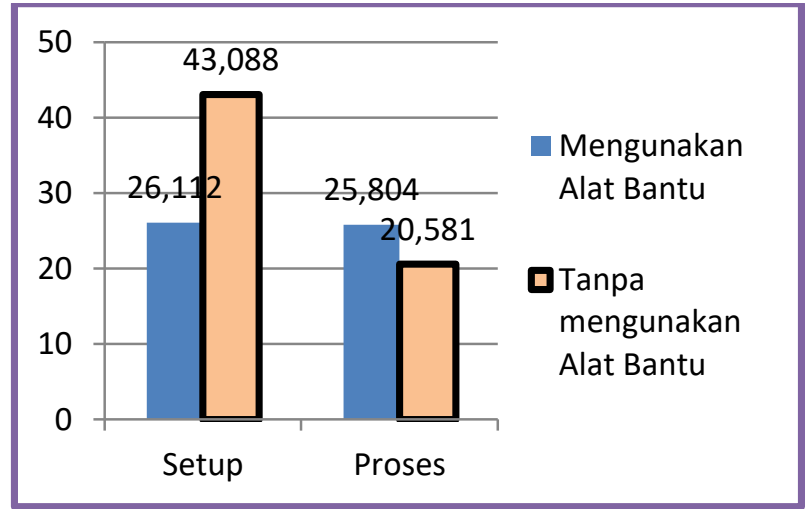

Gambar 11. Penggambaran grafik

perbandingan waktu setup dan waktu proses pengelasan. Dengan melihat grafik diatas dapat disimpulkan bahwa, waktu setup dengan 
menggunakan alat bantu meja putar roll Welding sebesar 21,619 detik, lebih cepat dibandingkan dengan tanpa menggunakan alat bantu yang memiliki waktu setup sebesar 43,088 detik. Hal ini dikarenakan alat bantu meja rol yang dibuat memudahkan operator dalam melakukan setup, sehingga waktu setup menggunakan alat bantu meja rol lebih efisien. Sedangkan waktu proses pengelasan menggunakan alat bantu meja putar rol sebesar 25,765 detik, lebih lama dibandingkan dengan tanpa menggunakan alat bantu meja yang memiliki waktu proses pengelasan sebesar 20,581 detik. Hal ini dikarenakan ruang gerak las yang sempit, sehingga proses pengelasan mengunakan alat bantu meja putar Roll Welding dilakukan 2 kali.

\subsubsection{Analisis Kelayakan Ekonomis Alat Bantu Meja Roll Welding}

Untuk dapat menganalisis apakah alat bantu yang dibuat cukup layak secara ekonomis, maka dilakukan pengujian dengan cara membandingkan ongkos dan waktu yang dibutuhkan dalam proses pengelasan menggunakan alat bantu meja putar las Roll Welding dan tanpa menggunakan alat bantu meja, dengan ukuran lot produksi sebanyak 2000 unit.

Tabel 3. Hasil Analisis Kelayakan Ekonomis

\begin{tabular}{|l|l|l|}
\hline \multicolumn{1}{|c|}{ Kriteria } & $\begin{array}{c}\text { Menggunakan } \\
\text { Alat bantu } \\
\text { meja putar las } \\
\text { roll welding }\end{array}$ & $\begin{array}{c}\text { Tanpa } \\
\text { Alat bantu } \\
\text { meja putar las } \\
\text { roll welding }\end{array}$ \\
\hline $\begin{array}{l}\text { Ukuran lot } \\
\text { produksi }\end{array}$ & 2000 unit & 2000 unit \\
\hline $\begin{array}{l}\text { Jumlah } \\
\text { benda } \\
\text { kerjaperjam }\end{array}$ & 69 unit/jam & 37 unit/jam \\
\hline $\begin{array}{l}\text { Ongkos } \\
\text { pembuatan } \\
\text { per unit }\end{array}$ & Rp. 286,-- & Rp. 446,- \\
\hline $\begin{array}{l}\text { Ongkos } \\
\text { tenaga kerja }\end{array}$ & Rp. 570.000,- & Rp. 792.000,- \\
\hline
\end{tabular}

Hasil perbandingan menunjukkan bahwa penggunaan Alat bantu meja las roll welding dapat meningkatkan volume produksi yang berakibat pada penurunan biaya pembuatan produk.

\subsubsection{Analisis Distorsi}

Setelah proses pengujian alat bantu Meja Putar pada benda uji berbentuk pelat strip dilakukan, benda uji tersebut akan diuji penyimpangannya atau distorsi dengan menggunakan dial indikator. Uji distorsi diambil dengan mengukur titik awal yang berarti titik nol pada ujung pelat strip dan diakhir pada titik akhir yaitu pada sambungan las. Parameter yang digunakan pada saat pengujian dapat dilihat pada tabel 4 .

Tabel 4. Parameter Pengujian

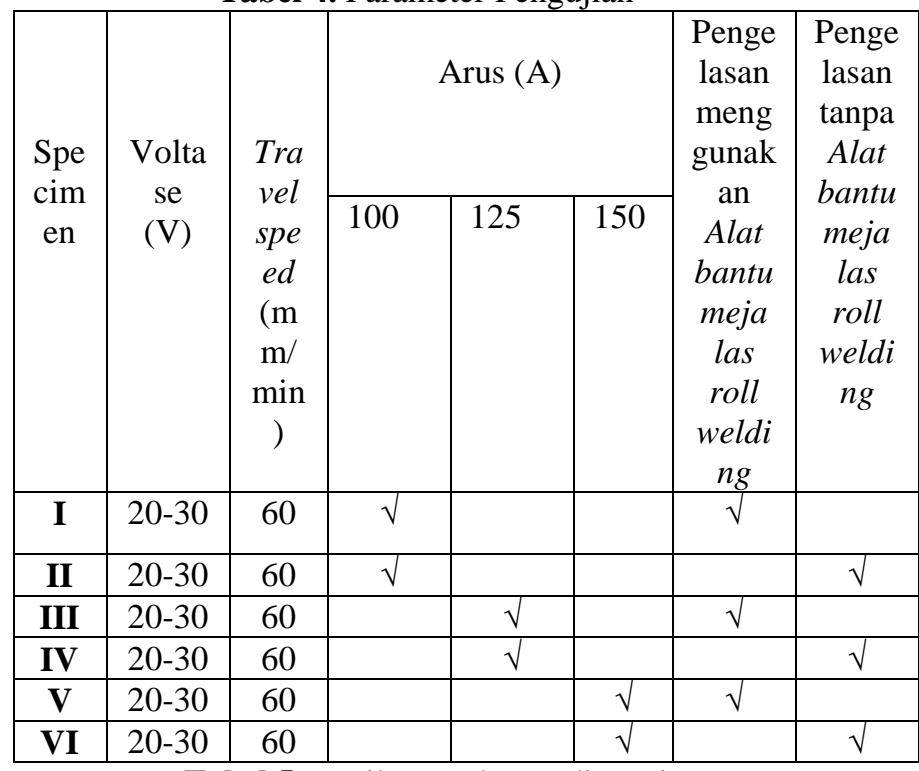

Tabel 5. Hasil pengukuran distorsi

\begin{tabular}{|c|c|c|c|c|c|c|}
\hline Specimen & I & II & III & IV & V & VI \\
\hline \multirow{6}{*}{$\begin{array}{l}\text { Distorsi } \\
\text { (derajat) }\end{array}$} & 0. & 0,5 & 0.6 & 1.9 & 1.3 & 2.5 \\
\hline & $\begin{array}{l}5 \\
5\end{array}$ & 8 & 6 & 7 & 3 & 1 \\
\hline & 0. & $\overline{0,6}$ & 0.3 & 1.5 & 1.9 & 2.4 \\
\hline & 5 & 5 & 3 & 0 & 6 & 0 \\
\hline & 0. & 0.5 & 0.3 & 1.8 & 2.2 & 3.68 \\
\hline & $\begin{array}{l}8 \\
8\end{array}$ & 9 & 5 & 1 & 0 & \\
\hline \multirow{2}{*}{$\begin{array}{l}\text { Rata-rata } \\
\text { (derajat) }\end{array}$} & 0. & 1.6 & 0.4 & 1.5 & 1.8 & 2.8 \\
\hline & $\begin{array}{l}6 \\
5\end{array}$ & 1 & 5 & 0 & 3 & 6 \\
\hline
\end{tabular}

Tabel 5. Merupakan hasil pengukuran pada pengujian benda uji nozzle setelah dilakukan proses pengelasan menggunakan alat bantu meja putar ROLL WELDING dengan variasi arus. 


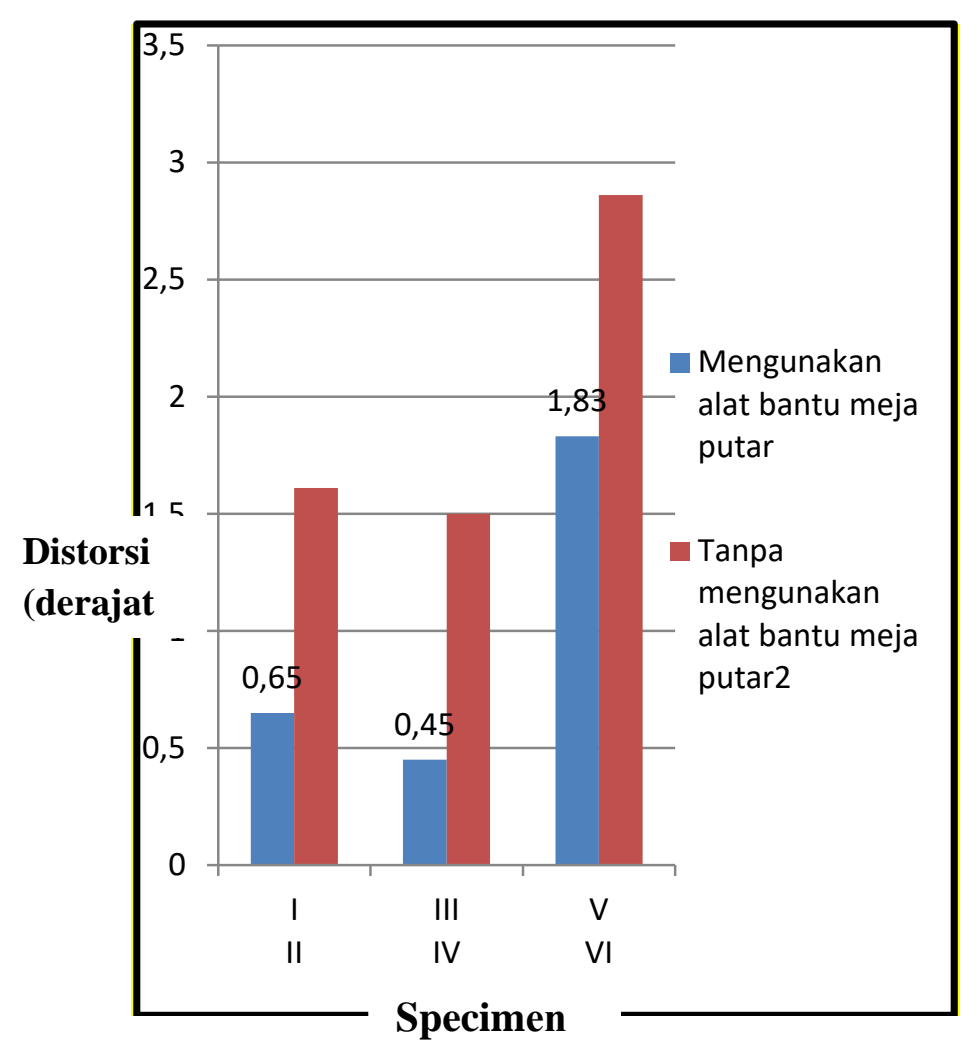

Gambar 12. Penggambaran grafik pengukuran distorsi.

\section{Kesimpulan dan Saran}

\subsection{Kesimpulan}

Kesimpulan yang didapat dari perancangan dan pembuatan alat bantu penyangga material yang praktis dan sesuai dengan kebutuhan segala posisi pengelasan yang akan memudahkan dan memberikan kenyamanan welder dalam mengelas.

Untuk proses pengelasan sambungan yang sudah dilakukan pengujian alat adalah sebagai berikut:

a. Pembuatan alat bantu MEJA ROLL

WELDING yang dihasilkan yaitu:

\section{ALAT BANTU PENGELASAN MEJA ROLL WELDING}

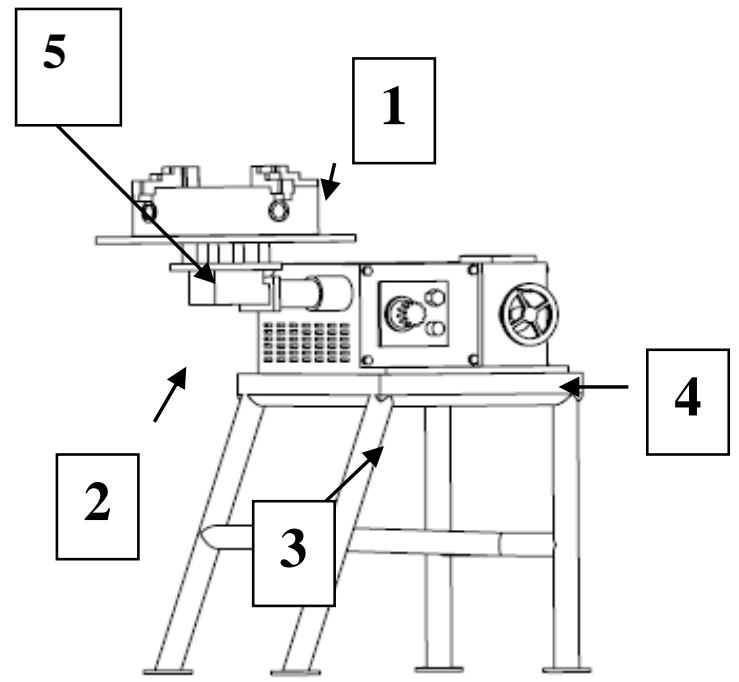

Keterangan Gambar:

1. Cekam

2. Lengan Meja Las

3. Rotor Speed

4. Handle Roda ,On Off, Speed Controll

5. Meja Putar

b. Alat bantu meja putar las ROLL WELDING dapat meningkatkan produktivitas melalui waktu

c. setup serta meningkatkan efisiensi penggunaan melalui penggunaan yang berulang-ulang.

d. Alat bantu meja las putar ROLL WELDING dapat mengurangi distorsi yang terjadi pada proses pengelasan sambungan

e. Pada proses pengelasan menggunakan alat bantu meja putar las ROLL WELDING, nilai distorsi terendah terjadi pada variasi arus $150 \mathrm{~A}$, yaitu sebesar 0,22 derajat. Sedangkan nilai distorsi tertinggi terjadi pada variasi arus $100 \mathrm{~A}$, yaitu sebesar 0,99 derajat.

f. Pada proses pengelasan tanpa menggunakan alat bantu meja putar las ROLL WELDING, nilai distorsi terendah terjadi pada variasi arus $125 \mathrm{~A}$, yaitu sebesar 1,44 derajat. Sedangkan nilai distorsi tertinggi terjadi pada variasi arus 150 A, yaitu sebesar 3,77 derajat. 
g. Semakin besar arus pada proses pengelasan menggunakan alat bantu meja putar las ROLL WELDING maka semakin kecil distorsi yang terjadi. Sedangkan pada proses pengelasan tanpa menggunakan alat bantu meja putar las ROLL WELDING semakin besar arus yang digunakan maka semakin besar pula distorsi yang terjadi.

\subsection{Saran}

Berdasarkan pengujian dan hasil yang didapatkan dari perancangan dan pembuatan alat bantu Meja putar las ROLL WELDING untuk proses pengelasan sambungan, maka penulis dapat memberikan saran yaitu :

1. Didalam melakukan perancangan alat tambahan pada mesin manufaktur perlu diperhatikan bentuk disain, ukuran dan dimensi alat. Agar alat dapat digunakan sesuai dengan apa yang diharapkan.

2. Alat bantu meja putar las ROLL WELDING ini dapat disempurnakan oleh peneliti selanjutnya, misalnya dengan memvariasikan jenis sambungan las.
And Basic Data. Manak

Bavan; Bureau Of Indian Standards. New Delhi 110002, India.

Rochim, T., 2007. PROSES PEMESINAN BUKU 1 Klarifikasi Proses, Gaya \& Daya Pemesinan. Penerbit : ITB. Bandung.

Wiryosumarto, Harsono dan Toshie Okumura. 2000. Teknologi Pengelasan. Cet.8. Jakarta: Pradnya Paramitha.

Yanis, Muhammad dkk. 2015. Perancangan dan Pembuatan Alat Bantu Cekam Pada Mesin Sekrap Untuk Mengerjakan

Proses Freis. Jurnal.

Akao, Yoji. 2014. Introduction to Quality Deployment (Application Manual of Quality Function Deployment . Japanese: JUSE Press.

Djati, Imam Widodo . 2013. Perencanaan dan Pengembangan Produk. Ull Press :

Jogjakarta.

Kotler, P. \& Amstrong, G. (2019). DasarDasar Pemasaran Edisi Kesembilan. Jilid Satu. Jakarta : PT Indeks.

\section{Daftar Pustaka}

ASM Handbook Commite. 1993. Welding, Brazing and Soldering. Vol. 6. ASM International.

Cross, Nigel. 1994. Engineering design methods: Strategies for product design. 2nd. ed. Chichester (Wiley).

Ginting, Rosnani. 2008. Perancangan Produk. Medan: Departemen Teknik Industri USU.

Hoffman, Edward G. 2004. "Jig and Fixture, Fifth Edition". Delmar, cangage learning, USA.

IS 14962. 2001. ISO General Purpose Metric Screw Threads-Tolerances: Part 1 Principles 
Kholiq $^{1}$, Ritonga ${ }^{2}$ / MATRIK Vol. XX Vol 1 September 2019 p:57-68

(Halaman ini sengaja dikosongkan) 